DOI: https://doi.org/10.47405/mjssh.v5i1.357

\begin{tabular}{|c|c|}
\hline 4 & Malaysian Journal of Social Sciences and Humanities (MJSSH) \\
\hline $\begin{array}{l}\text { Malaysian Journal of } \\
\text { Social sciences and }\end{array}$ & Volume 5, Issue 1, January 2020 \\
\hline (MJ-SSH) & e-ISSN : 2504-8562 \\
\hline & $\begin{array}{l}\text { Journal home page: } \\
\text { www.msocialsciences.com }\end{array}$ \\
\hline
\end{tabular}

\title{
ESL Learners' Enhancement of Standard English Accent Among Khotimul Quran of A Primary School Students in Malaysia
}

\author{
Nurul Atasha Binti Mohd Nordin'1, Kamariah Binti Yunus ${ }^{1}$ \\ ${ }^{1}$ Faculty of Languages and Communication, Universiti Sultan Zainal Abidin (UniSZA) \\ Correspondence: Nurul Atasha Binti Mohd Nordin (nurulatashamohdnordin@yahoo.com)
}

\begin{abstract}
CEFR (Common European Framework of Reference for Languages) is a new syllabus for English language subject of Malaysia primary school students. However, none of pronunciation elements involve the stress, rhythm and intonation have been emphasized to accomplish Standard English Accent. The issue is that, Malaysian primary school students do not apply correct stress and intonation while speaking and reading Standard English. Therefore, this study aims to identify the use of stress, rhythm and intonation applied in their spoken English words by both groups. The researcher had choose 15 Khotimul Quran students as the experimental group, whose background had complete reciting Quran for the whole $30 \mathrm{Juz}$ and 15 common students as the control group from Sekolah Kebangsaan Pusat Air Tawar, Johor as the unit of analysis. The researcher uses semi-structured interview, observation and focus group discussion to triangulate the data. Pilot data analysis of the responses had shown a strong correlation between speaking Standard accent with correct stress, rhythm and intonation among the Khotimul Quran. Based on this results, the researcher expects the experimental group those who have Quranic-phonological background achieves higher percentages of accurateness of speaking Standard English accent compares to the control group.
\end{abstract}

Keywords: standard english accent, stress, rhythm, intonation

\section{Is your English Standard Enough?}

Standard English accent is the behaviors of pronouncing the words in English according to its stress, rhythm and intonation. It is a distinct emphasis given to a syllable or word in speech by stress or pitch. Cambridge Dictionary added accent is defined as a special emphasis given to a particular syllable in a word, word in a sentence, or note in a set of musical notes. English accent is spoken according to the mark on the syllables of its phonetic diagrams. For Malaysian who spoke Malay language as their first language, there would be a problem which acquire them to learn the "music" of English. Malay language is distinctively different from English accent which is monotonous. Therefore, there are no mark of stress, rhythm or intonation exist as in the phonetics diagrams of the words.

As the students of Malaysian are majority speaking their mother tongues, they need to learn correct pronunciation according to the words stress rhythm and intonation in English lessons. As the results, the conversations happened to break down and dismissed. "Intelligible pronunciation is vital to successful communication" (Levis \& Grant, 2003, p. 13) as cited in (Haasch, 2016). Unfortunately, there are none of pronunciation subjects or slots guided by the Malaysia Ministry of Education which being taught by the English teachers in classes. Therefore, the pronunciation of the students cannot be 
taught in perfect lessons. The researcher wants to approach this issue in order to enhance the students' speaking and reading in appropriate Standard English accent. Without a trained ear, a layperson may not employ the skills necessary for this mental processing of stress errors, thus a breakdown in communication ensues (Haasch, 2016). One of this errors is recorded in other researches too. In instance, Munro and Derwing, which stated that, such errors might affect successful communication more than errors in individual consonant or vowel sounds (Munro \& Derwing, 1999).

Almost in every lesson of English lessons in schools, the students' pronunciation aspect is often "ignored" and specified by the teachers. Pronunciation is an easily overlooked aspect of language when teaching a given language (Antti Rajamaki, 2016). Therefore, the pronunciations of the students are being neglected in order to give the chances for them to speak and read in English. At the same time, students learn by themselves without appropriate teacher as the monitor. It is assumed that students pick it up independently when they use and hear the language (Derwing and Munro, 2014 as cited in Rajamaki, 2016). Thus, investigating pronunciation practices on the perspectives of teachers' beliefs would provide an understanding of the dilemma surrounding the issues of pronunciation instructions. To teach with correct stress, intonation and rhythm in speaking would fulfill the rubrics of Standard English Accent.

According to Cargile and Giles (1998) as cited in (Bauman, 2013), "Spanish-accented, Appalachian, and AAVE varieties are consistently downgraded on status-related measures, but equally well liked as Standard American English speakers; Norwegian- and Italian-accented speakers are downgraded on measures of both status and attractiveness; while British and Malaysian varieties are rated favorably on status-related measures but downgraded on attractiveness."

The results stated that, “...while British and Malaysian varieties are rated favorably on status-related measures but downgraded on attractiveness." In the researcher's point of views, this happened due to the first language accent and the regions dialects. Therefore, it leads to less accurate of pronouncing in correct stress, rhythm and intonation which sometimes results in misunderstanding and ambiguity. Apart from this, these situations will get worsening if the situations while conversations take place are not clearly stated. This issues has become a highlight which bringing the researcher towards a study on practicing a standard accent of English.

Standard English is defined as the English with accurate grammar and structures used by a speaker. But nowadays, many of us do think Standard English is the English with accents which are used only by the native speakers. Linguist and author Rosina Lippi-Green refers to this as "the standard language ideology", (Rosina Lippi-Green as cited in Chi Luu, 2017), where many people believe the dialect with the highest social prestige is also the only correct and valid form of the language. But actually, it is not. In fact, all dialects and accents are linguistically valid (Rosina Lippi-Green as cited in Chi Luu, 2017). What made they think such a way is because those ESL speakers are speaking by their first language accents who exposed their nationality while speaking or reading English. Listener evaluations of foreign-accented voices, then, are likely to reflect their attitudes toward non-native speakers generally, and toward members of the cultural group indicated by the accent more specifically (Carina Bauman, 2013). Then, the speaking and reading can be only better of Standard English Accent if the stress, intonation and rhythm are well corrected and associated among the ESL speakers.

Even though pronunciation differs, meanings of the same words often remain the same. "Differences between accents are of two main sorts: phonetic and phonological. When two accents differ from each other only phonetically, we find the same set of phonemes in both accents, but some or all of the phonemes are realized differently. There may also be differences in stress and intonation, but not such as would cause a change in meaning (Roach, 2009).

"Many accents of English also differ noticeably in intonations without the difference being such as would cause a difference in meaning; some Welsh accents, for example, have a tendency for unstressed syllables to be higher in pitch than stressed syllables. Such a difference is, again, a phonetic one..." "Phonological differences are of various types...Within the area of segmental phonology the most obvious type of difference is where one accent has a different number of phonemes (and hence of 
phonemic contrasts) from another (Roach, 2009). For a situation given, "You are being too Malay" or "She is a Mexican by the way she talked to me". Non-native language varieties are, by definition, nonstandard (Carina Bauman, 2013). To speak with the first language accent is not an error but the best would be speaking and reading in Standard English accent which make your recipients understand you at ease. While non-standard pronunciation may be generally downgraded, not all foreign accents receive the same evaluation (Bauman, 2013).

To create consciousness and concern for pronunciation, Kenworthy (1987) has referred that, English pronunciation is comprised of various components like sounds, stress and variation all together, so the learners need to recognize the function as well as the structure of it. Besides, they need to develop a consciousness for pronunciation and also need to be aware of that their poor and unintelligible language can make their utterances annoying to themselves and to their listeners as well (p. 2).

There are some obvious issues regarding this pronunciation predicaments which have been issued by other researchers. There predicaments involved are stated as follows: stress, rhythm and intonation in a word of English.

\section{Malaysian Students' English towards Standard English}

As for Malaysia of its English language development, there are a few changes in the curriculum structures since The Independence. From KBSR, KSSR and current, CEFR. (Malaysia Ministry of Education 2013-2025 Blueprint, pg. 112, 2013). The curriculum structures, framework, and specifications are in particularly justified according to the skills of listening, speaking, reading, writing, grammar, language arts and language awareness (year 3 and above) (CEFR CURRICULUM SPECIFICATION, 2018). The days of teaching is arranged as the skills arrangement above. According to text given, the stimulus given are to be more of pictures compared to the words for the students to read (CEFR BOOK 1, 2018). These are clearly shown that the products of the tests are giving more chances for the students to speak and read more in order to apply and master the second language acquisition. This is however, none of pronunciation elements in such stress, rhythm and intonation that has been strengthen in any of those syllabi of teachers' documents introduced by the Ministry of Education. It means that are no guidance prepared for the teachers to teach the students with correct pronunciations of which the stress, rhythm and intonation are being stressed.

Firstly, Malaysian primary school students incorrectly pronounce words of Standard English Accent. They will pronounce the words as what they had guess according to the letters arrangement in the words they uttered or read. This is among the major errors in pronunciation predicaments which completely alter the area of vocabulary, sounds and meanings of the words. It might be understood if everyone is looking at the texts and they pronounce the same too. Some of the students do not know the stress placement therefore they do not know how to differentiate between the sounds of PREfer and preFER words. They pronounce the word with incorrect stress and rhythm placement. Regarding this issue, Sadia stated in her article that, inappropriate pronunciation of English will make people misunderstand the speaker easily, (Sadia, 2015, p.36, as cited in Jahan n.d).

Secondly, Malaysian primary school students do not apply correct stress and intonation while speaking and reading Standard English. Rahman as cited in Hoque, (2011) has found that in Bangladesh, English is spoken more likely with an accent associated with mother tongue that ignores the sound patterns, stress, rhythm and the intonation systems of English (p. 8). On the other hand, Sultana and Arif (as cited in Hoque, 2011) have pointed out a number of reasons of Bengali learners' mispronunciation, such as lack of their knowledge about the difference between the letters and sounds of a word. Sadia claims that, most of the teachers do not give any effective tasks for pronunciation practice during the class period (Sadia, 2011). It is quite impossible to make one's pronunciation, intonation and stress perfect by only theoretical knowledge because the achievement of a desired standard needs a lot of practice (p. 13). 
Thirdly, Malaysian primary school students are speaking English in their accents which influenced by their first language. Therefore, some of the accents are too "nationally" until exposing who they are of where they are from and their nationality. According to Khan (2007) as cited in Sadia (2015), due to various phonological differences in L1, pronunciation patterns of learners' L2 often get influenced ( $p$. 7). That is not a problem but it would when the English words they produced cannot be understood at all, deviated in meaning and misunderstood by intonations and stress of the words uttered. Sadia Khatun Sara had also stated in her study that some students cannot achieve the proper pronunciation due to the influence of their local (Sylheti) accent or it can be the teachers' local accent influence that makes the students adapt the wrong pronunciation (Sadia, 2015). According to Nunan (as cited in Jahan, n.d), teaching pronunciation is dealt from different perspective because impact of the first language seems prominent in case of pronunciation and only exceptional learners can achieve the mastery over pronunciation.

Fourthly, Malaysian primary school students speak with their mother tongue dialects. Malaysia country consists of 14 states with different dialects. Some are similar and some are distinctively difference. Those dialects are states of Kedah, Terengganu, Kelantan and Negeri Sembilan. They are so difficult to understand if you are not locals and kind of learning a new other language. The list of Malay dialects including the hint of a closer relationship among Kedah, Perlis, and Penang -forms the accepted canon of Malaysia's Malay dialects (James T.Collins). Shuchi (2013) as cited in (Sadia, 2015) also added that, it is difficult to teach Standard English in the classroom because the teacher has to face many problems due to the dialectal accent of students (p. 8). Listeners who are even Malaysians needs to study different lessons instead of only the standard Malay language. As for these speakers with those dialects are quite difficult to separate them from the dialects in English lessons. The English uttered are attached with the dialects they have.

Fifthly, Malaysian primary school students English language teaching are always emphasizes on writing instead of speaking and reading. According to Hoque (2011), teachers only give importance to the reading, writing and grammar sections of the textbooks that are relevant to passing the SSC and HSC examinations (p. 2). Therefore, the pronunciation are not thoroughly taught in class except for reading lessons. Jahan (n.d) stated that, sometimes teachers emphasize on teaching only the enunciation of difficult sounds and allow the class to produce native like sounds, although this effort does not work among the learners after the semester (p. 2). Moreover, Shuchi (2013) as cited in (Sadia, 2015) added that some teachers might have lack of qualification and that is why they might not aware of their own English language (p. 9).

\section{Exploring an Idea to Enhance Standard English among Malaysian Students}

Word stress in English is very systematic (Haasch, 2016). Factors that influence where stress is placed within a word may include a word's origin, prefixes, suffixes, and the grammatical function (i.e., reflexives, numbers, compounds, and phrasal verbs) within an utterance (Celce-Murcia et al., 2010). Besides, stress is also defined as the use of extra respiratory energy during a syllable (Al-Syamaleh, 2014). He added that stressed syllable is produced by pushing more air out of the lungs in one syllable relative to the others. Therefore a stressed syllable is often heard in louder and higher pitch, with a longer vowel than the unstressed. Stressing are needed to give special emphasis to a word or to contrast a word with another, to indicate the syntactic relationships between words or parts of words. And to differentiate between a compound noun and an adjective followed by a noun syllable (Al-Syamaleh, 2014). Since English language words, phrases and sentences are unpredictable compared to Malay language, this creates ignorance of correct pronunciation among Malaysian primary school students while speaking and reading in Standard Accent of English. As a result of this issue, the researcher would take it into focus in identifying and examining their stress uses along the observations. When a vowel is produced in an unstressed syllable, the vowel is often "very short and unclear in English" (Avery \& Ehrlich, 1992a, p. 106). An unstressed vowel is pronounced as schwa, or a reduced vowel, and the schwa is represented by the phonetic symbol /a/ (Burns, Avery, \& Ehrlich, 1992) as cited in (Haaach, 2016). Compared to unstressed syllables, it would not be a big issue as the first language, Malay language is monotonous which does not prioritize stress except in given punctuations. 
Rhythm, in English, is comprised of stressed and unstressed syllables, the reduction of function words (Avery, Ehrlich \& Jull, 1992), and features of connected speech (Celce-Murcia et al., 2010).

Connected speech, alone, is comprised of contractions, blends, and reductions, as well as linking words and phrases, assimilation, dissimilation, deletion, and epenthesis (Celce-Murcia et al., 2010). Unlike the first language of the subjects, which is Malay language, there are no specific stress, rhythm and intonations in a word before they are put into punctuations or some of states dialects which involve stress, rhythm and intonations. In order to understand rhythm, one must be familiar with its components.

Ladefoged, 1993 as cited in syllable (Al-Syamaleh, 2014), tone is defined as the pitch in a property of auditory that enables a listener to place on a low to high in ignorance of acoustic properties in such, the sound frequency which conveys parts of the word meanings.

Meanwhile, intonation is pattern of pitch changes that occur in a certain phase which might be a completed sentence syllable (Al-Syamaleh, 2014). He added that tone and intonation belong to the word and word group. Therefore, their use affects the whole meaning of the word group. These tones includes the falling tone (the Glide-down tone).

Wennerstrom (2001) referred to intonation as the melody created by the voice while producing a speech, giving the opportunity to the speaker to choose their pitch according to what he/she wants to express in his/her utterance. Wennerstrom (2001) divided intonation into four categories: pitch accents, pitch boundaries, key, and paratones. Pitch accents refer to the different kinds of tones that will be used by the speaker; in other words, it is the stress of the pronounced word. Pitch boundaries, on the other hand, refer to the lengthening of the ending of the word or utterance, also identified as rising or falling intonation (Wennerstrom, 2001) Key indicates the attitude of the speaker towards a previous utterance. High key indicates contrast response while mid key indicates neutral, and low key refers to not having new information for uttering a response. Finally, paratones represent the narrowness or wideness of the pitch range (Maria, 2013).

The researcher needs to go through all these previous studies so that she can improve and enhance the pronunciation of English among Khotimul Quran. The techniques proposed in the opportunistic pronunciation teaching from the previous studies would be applied in the accent lessons. The background of the students among the Khotimul Quran who speak Malay Language as the first language and English Language as the Second Language. As the study proceeds, the researcher would apply the language transfer elements from L1 and Quranic Recitation Practices. Therefore, there would results in adaptation of cross-language-transfer as the previous studies proposed above, within the first language and the acquisition of the second language was done to investigate the relationship and the relevance.

\section{Purpose of the Study}

This research is carried out to study on the ESL learners' enhancement of Standard English. Accents through English Accent lessons among Khotimul Quran of primary school students.

\section{Objectives of the Study}

The overall aim of this study is to study the factors of mispronounce words by referring to stress, rhythm and intonation in speaking English as the second language. Besides, the researcher will be conducting accent lessons to enhance the speaking and reading by using Standard English Accents among the Khotimul Quran of primary school students thereby provide recommendations for improvement of the students' fluency. 


\section{Research Objectives:}

i. To identify the use of stress, rhythm and intonations among Khotimul Quran and Control Group of primary school students.

ii. To examine the English accent spoken and read among Khotimul Quran and Control Group by referring to the stress, rhythm and intonations used of primary school students.

iii. To investigate the factors of incorrect stress rhythm and intonations used in spoken and read English accent among Khotimul Quran and Control Group of primary school students.

\section{Research Question}

i. What are the common mistakes in stress, rhythm and intonation used identified in speaking and reading English among the primary school students?

ii. How the stress, rhythm and intonation are use in speaking and reading English among Khotimul Quran primary school students?

iii. What are the factors of incorrect use of stress, rhythm and intonations in speaking and reading in Standard English accent among the primary school students?

\section{Methodology}

\section{Experimental Group vs Control Group}

The sample taken type is purposive. They are chosen based on the study requirements in order to collect the data needed for completing this study. Therefore, the experimental group is chosen among those who has knowledge about the rules of reciting Quran and complete his recitation of the whole verses of the Quran. Meanwhile the control group is chosen among those who has little or none on the knowledge about the rules of reciting Quran and does not complete his recitation of the whole verses of the Quran.

\section{Type of Study}

As the samples are in two groups, the researcher conducts experimental study. This study method requires the use of all qualitative methods to collect and analyze the data collected. In such a way which researcher will conduct a purposeful sampling, collection of open-ended data, analysis of text or pictures, representation of information in figures and tables, and personal interpretation of the findings all form of qualitative methods (Cresswell, 2014). Therefore, the researcher had choose the experimental study to make comparisons.

The data collected from the interviews data, observations data, recordings data, and document data would be coded, tabulated, analyses and classified according to the themes and patterns. The preliminary data collected are used to support the data collected from the pilot test.

\section{Pilot Test}

For this time being, the researcher had conducted a pilot test among the 30 subjects as the samples. All of them had undergo a pre-test which involve four levels of word production development which needed them to say words, phrases, sentences and a short paragraph in sequences of the four levels. As the pilot test went on, there were pre-test, and post-test. Before the researcher conducting the post-test, she had conduct an accent lesson which involved the four levels of pronouncing. The same items were used to make comparisons between the experimental group and the control group. 
There are 15 students who are among Khotimul Quran and 15 among common students. There are 12 years old students which are in the last year of primary school. Upon the result, the researcher could see that the experimental group got more accurate used of stress, rhythm and intonation of Standard English of the four levels.

Besides, from the results reviewed on language level performance (LLP) of class level, and CEFR band, all of the students from the experimental group had achieved the highest level of LLP band 6 and CEFR band A2.

\section{Is It Wrong To Speak And Read With Accent English?}

According to Munro and Derwing (1999), heavily accented speech may sometimes be intelligible, while suprasegmental errors (stress, intonation, and rhythm) may have more of an effect on intelligibility than segmental errors (phonetic errors). For example, if a speaker were to say begetables instead of the word vegetables, they have made a segmental error by mispronouncing $/ \mathrm{v} /$ as $/ \mathrm{b} /$ (Haasch, 2016). This would be common heard among the students to utter the wrong vowels but if it involves the wrong placement of stress and rhythm of the word, it may sound even unintelligible. When the speaker fails to use correct placement of syllable and word stress in conjunction with accurate vowel reduction, thus not creating the expected rhythm of English, communication often breaks down (Haasch, 2016).

A well-planned English teacher must has her own way of strategies or techniques to give the best to deliver the lesson (Rosenshine and Frust, 1973) as cited in Yun Ho Shinn, 1997) reported that students learn best when the following characteristics are present: variability in teaching methods and materials, interest, clarity, task-oriented behavior, teacher use of structuring comments, student opportunity to learn the material, multiple levels of questions, and enthusiasm. Thus, the lessons of pronunciation should include above elements to produce Standard Accent of English while speaking and reading to fulfill the second language acquisition among the Malaysian primary school students.

Almost in every lesson of English lessons in schools, the students' pronunciation aspect is often "ignored" and specified by the teachers. Pronunciation is an easily overlooked aspect of language when teaching a given language (Antti Rajamaki, 2016). Therefore, the pronunciations of the students are being neglected in order to give the chances for them to speak and read in English. At the same time, students learn by themselves without appropriate teacher as the monitor. It is assumed that students pick it up independently when they use and hear the language (Derwing and Munro, 2014 as cited in Rajamaki, 2016). Thus, investigating pronunciation practices on the perspectives of teachers' beliefs would provide an understanding of the dilemma surrounding the issues of pronunciation instructions. To teach with correct stress, intonation and rhythm in speaking would fulfill the rubrics of Standard English Accent.

According to Cargile and Giles (1998) as cited in (Bauman, 2013), "Spanish-accented, Appalachian, and African-American Vernacular English (AAVE) varieties are consistently downgraded on statusrelated measures, but equally well liked as Standard American English speakers; Norwegian- and Italian-accented speakers are downgraded on measures of both status and attractiveness; while British and Malaysian varieties are rated favorably on status-related measures but downgraded on attractiveness."

The results stated that, “...while British and Malaysian varieties are rated favorably on status-related measures but downgraded on attractiveness." The question is why is that Malaysian accent has been in less-attractiveness. From the researcher own experiences and personal views, our accent has been in less accurate of pronouncing in correct stress, rhythm and intonation which sometimes results in misunderstanding and ambiguity. This might be influenced by the factors of the first language accents and dialects of states and regions in Malaysia. Apart from this, these situations will get worsening if the 
situations while conversations take place are not clearly stated. This issues has become a highlight which bringing the researcher towards a study on practicing a standard accent of English.

Standard English is defined as the English with accurate grammar and structures used by a speaker. But nowadays, many of us do think Standard English is the English with accents which are used only by the native speakers. Linguist and author Rosina Lippi-Green refers to this as "the standard language ideology", (Rosina Lippi-Green as cited in Chi Luu, 2017), where many people believe the dialect with the highest social prestige is also the only correct and valid form of the language. In fact, all dialects and accents are linguistically valid (Rosina Lippi-Green as cited in Chi Luu, 2017). But actually, it is not. What made they think such a way is because those ESL speakers are speaking by their first language accents who exposed their nationality while speaking or reading English. Listener evaluations of foreign-accented voices, then, are likely to reflect their attitudes toward non-native speakers generally, and toward members of the cultural group indicated by the accent more specifically (Carina Bauman, 2013). Then, the speaking and reading can be only better of Standard English Accent if the stress, intonation and rhythm are well corrected.

Even though pronunciation differs, meanings of the same words often remain the same. "Differences between accents are of two main sorts: phonetic and phonological. When two accents differ from each other only phonetically, we find the same set of phonemes in both accents, but some or all of the phonemes are realized differently. There may also be differences in stress and intonation, but not such as would cause a change in meaning (Roach, 2009).

"Many accents of English also differ noticeably in intonations without the difference being such as would cause a difference in meaning; some Welsh accents, for example, have a tendency for unstressed syllables to be higher in pitch than stressed syllables. Such a difference is, again, a phonetic one..." "Phonological differences are of various types...Within the area of segmental phonology the most obvious type of difference is where one accent has a different number of phonemes (and hence of phonemic contrasts) from another (Roach, 2009). For a situation given, "You are being too Malay" or "She is a Mexican by the way she talked to me". Non-native language varieties are, by definition, nonstandard (Carina Bauman, 2013). To speak with the first language accent is not an error but the best would be speaking and reading in Standard English accent which make your recipients understand you at ease. While non-standard pronunciation may be generally downgraded, not all foreign accents receive the same evaluation (Bauman, 2013).

To create consciousness and concern for pronunciation, Kenworthy (1987) has referred that, English pronunciation is comprised of various components like sounds, stress and variation all together, so the learners need to recognize the function as well as the structure of it. Besides, they need to develop a consciousness for pronunciation and also need to be aware of that their poor and unintelligible language can make their utterances annoying to themselves and to their listeners as well (p. 2).

\section{How the sounds of Quran relates to the stress, rhythm and intonation of Standard English?}

Based on the issues encountered below and the results of the pilot test, the researcher would like to discover the relations between the rules of Quranic recitations (tajweed) with the stress, rhythm and intonation in English. In addition, the researcher would like to further her study in the knowledge of manners of reciting Quran (Qiraat) and the melody of reciting Quran (Tarannum or Maqaamaat) to find the connections between stress, rhythm and intonation of Standard English. Therefore, these data might triangulate with the raw data from the pilot test.

In the nutshell, there are some reasons why we need to speak in Standard English accents. Being the speaker of English as the second language must be clear and fluent to let other to understand our messages. As defined, Standard English is the English that with respect to spelling, grammar, pronunciation, and vocabulary is substantially uniform though not devoid of provincial differences. Besides, it is well recognized by the usage in the formal and informal speech and writing of the 
educated, and that is widely recognized as acceptable wherever English is spoken and understood. Last but not least this might help the speakers to socialize with the other speakers by using the language of Standard English accent. The confidence they have gained from the study proposed approach is raised and able them to make a step forward to speak and read. This will also help to build their social skills in the future and develop the people to be as the same par as other country people worldwide.

\section{References}

Al-Shamayleh, T. S. (2014). Improving The Quality Of Teaching English Stress And Intonation To University Students Who Are Learning English As A Foreign Language Using Multimedia. European Scientific Journal September, 10(25), 1857- 7431, 207-228.

Bauman, C. (2013). Social Evaluation of Asian Accented English. 19(2),12-20.

Haasch, A. L. (2016). Teaching English Rhythm: The Importance of. Minesota: Hamline University.

Hoque, A. B. (2016). English Pronunciation Problems Of The Tertiary Level Students In Bangladesh: A Case Study. International Refereed Research Journal , 7(61), 50-61.

Kenworthy, J. (1987). Longman Handbook forLanguage Teachers:Teaching English Pronunciation. London: Longman.

KPM. (2013). Kementerian Pendidikan Malaysia. Retrieved from Dasar KPM: https://www.moe.gov.my/images/dasar-kpm/articlefile_file_003108.pd

Marianne Celce-Murcia, D. M. (2010). Teaching Pronunciation: A Course Book and Reference Guide Second Edition. . In D. M. Marianne Celce-Murcia, Teaching Pronunciation: A Course Book and Reference Guide Second Edition. . Cambridge.

Nurul Fatehah Mohamad Uri, M. S. (2018). Implementation of CEFR in Malaysia:. 3L: The Southeast Asian Journal of English Language Studies, 24(3), 168-183.

Rajamaki, A. (2016). Pronunciation teaching in a Finnish secondary school: A case Study. 4-19.

Roach, P. (1998). English Phonetics and Phonology. United Kingdom: Cambridge University Press.

Roach, P. (2009). English Phonetics and Phonology 4th edition (Cambridge). In English Phonetics and Phonology 4th edition (Cambridge).

Sara, S. K. (2015). English Pronunciation Difficulties of Students in the Sub-Urban Areas of Sylhet: A. $1-9$.

Shinn, Y. H. (1997). Teaching strategies, their use and effectiveness as perceived by teachers of agriculture:A National Study. Retrospective Theses and Dissertations. 12244., 1-138.

T.Collins, J. (1989). Malay Dialect Research In Malaysia:The Issue Of Perspective. In J. T.Collins, Malay Dialect Research in Malaysia (pp. 235-264). 